\title{
O Movimento de Formação Docente no Ensino de Geometria nos Anos Iniciais
}

\author{
Anemari Roesler Luersen Vieira Lopes' \\ Halana Garcez Borowsky Vaz' \\ 'Universidade Federal de Santa Maria (UFSM), Santa Maria/RS - Brasil
}

RESUMO - O Movimento de Formação Docente no Ensino de Geometria nos Anos Iniciais. Neste artigo, discorremos sobre a organização de um grupo do qual participavam quatro professoras que planejaram, desenvolveram e avaliaram uma proposta de ensino. Nosso intuito foi discutir sobre a formação de professores que ensinam matemática nos anos iniciais, tendo em vista os desafios de organizar uma Atividade Orientadora de Ensino de Geometria. Para isso, pautamo-nos nos pressupostos da Teoria Histórico-Cultural, e, especificamente da Teoria da Atividade (Leontiev, 1983; 1988) e da Atividade Orientadora de Ensino (Moura, 1996; 2010). Foi possível evidenciar que o conhecimento matemático das docentes atuou como norteador das ações e que o compartilhamento destas mostrou-se como preponderante para que se constituíssem como formadoras.

Palavras-chave: Formação de Professores. Anos Iniciais do Ensino Fundamental. Educação Matemática. Ensino de Geometria.

ABSTRACT - The Movement of Teachers' Education for Geometry Teaching in the Elementary School. This paper reports the organization of a group of four teachers who planned, developed, and evaluated a teaching proposal. The aim of this study was to discuss the education of teachers who teach mathematics for the Elementary School, considering the challenge of organizing a Guiding Activity for Geometry Teaching. In order to do so, the researchers referred to the Historical-cultural Theory, more specifically to the Activity Theory (Leontiev, 1983; 1988) and the Educational Guiding Activity (Moura, 1996; 2010). It was possible to show that the teachers' mathematical knowledge served as guidance for the teaching practices, and that their sharing proved to be preponderant for their constitution as teachers. Keywords: Teachers' Education. Elementary School Education. Mathematics Education. Geometry Teaching.

Educação \& Realidade, Porto Alegre, v. 39, n. 4, p. 1003-1025, out./dez. 2014.1003 Disponível em: <http://www.ufrgs.br/edu_realidade> 
O Movimento de Formação Docente no Ensino de Geometria nos Anos Iniciais

\section{Introdução}

A formação, os conhecimentos e a atuação dos professores dos anos iniciais do Ensino Fundamental, frequentemente, são postos à prova e questionados, principalmente perante a publicação dos baixos índices de aprovação dos alunos, ou os resultados das avaliações externas de matemática. Devido ao fato de esses índices serem desanimadores, é atribuída aos professores a responsabilidade de não ter ensinado os conhecimentos básicos dessa disciplina. Por vezes, a explicação mais recorrente, advinda do senso comum, é a de que tais profissionais simplesmente não sabem matemática ou não se interessam em buscar esses conhecimentos.

A justificativa do fracasso da matemática centrada unicamente no professor merece um olhar mais apurado na medida em que várias pesquisas vêm apontando que os problemas quanto ao ensino de matemática estão fortemente relacionados à formação docente. Curi (2005), em suas investigações com professores dos anos iniciais constatou que, apesar do decorrer do tempo, não foi dada a atenção necessária à construção dos conhecimentos matemáticos para ensinar, mas à maneira mecânica de repetir sempre da mesma maneira o ensino. Além disso, outra questão, apontada por Nacarato, Mengali e Passos (2009), é a de que os professores desse nível de ensino têm tido poucas oportunidades para uma formação matemática que possa fazer frente às exigências da educação. Ademais, quando ela ocorre na formação inicial, pauta-se mais nos aspectos metodológicos do que nos relacionados aos conhecimentos matemáticos.

Como formadoras de professores vivenciamos em nossa trajetória tais constatações e convivemos com a fragilidade dos cursos de formação de professores, tanto inicial quanto continuada, o que nos levou a refletir e preocupar-nos com esta situação. Partindo dessas preocupações, nosso grupo de estudos e pesquisas tem direcionado suas ações para os processos de ensino e aprendizagem da matemática nos primeiros anos de escolaridade. Nesse artigo, apresentamos parte de uma de nossas investigações vinculadas a um projeto interinstitucional desenvolvido no âmbito do Observatório da Educação da Coordenação de Aperfeiçoamento de Pessoal de Nível Superior (CAPES) ${ }^{1}$ e que tem como espaço o Clube de Matemática. Com o principal objetivo de discutir sobre a formação de professores que ensinam matemática nos anos iniciais do Ensino Fundamental tendo em vista os desafios de organizar uma Atividade Orientadora de Ensino de Geometria, apresentamos este texto em três partes. Inicialmente, trazemos uma breve discussão dos fundamentos teóricos que norteiam os nossos estudos, são eles: a Teoria Histórico-Cultural, a Teoria da Atividade (Leontiev, 1983; 1988) e, mais especificamente, a Atividade Orientadora de Ensino (Moura, 1996; 2010). Essa explicitação faz-se relevante ao esclarecer de quais pontos partimos para o encaminhamento das ações e a análise dos dados. $\mathrm{Na}$

1004 Educação \& Realidade, Porto Alegre, v. 39, n. 4, p. 1003-1025, out./dez. 2014. Disponível em: <http://www.ufrgs.br/edu_realidade> 
segunda parte, focamos a organização de um grupo de professoras ${ }^{2}$ dos anos iniciais visando ao ensino de Geometria e, para isso, apresentamos as docentes e discutimos sobre o seu planejamento, seu desenvolvimento e sua avaliação referentes a uma Atividade Orientadora de Ensino. Finalizamos com algumas considerações tecidas a partir dos dados apresentados.

\title{
Alguns Pressupostos Teóricos
}

A escola é entendida por nós como o local social privilegiado para a apropriação de conhecimentos produzidos historicamente. Nesse sentido, segundo Moura et al. (2010), a ação do professor deve estar voltada intencionalmente para esse fim, concretizando, assim, objetivos sociais do currículo escolar. Para isso, a organização do ensino implica que o professor defina ações, eleja instrumentos e avalie o processo de ensino e aprendizagem. Destarte, conforme os autores,

\begin{abstract}
[...] embora o sujeito possa se apropriar dos mais diferentes elementos da cultura humana de modo não intencional, não abrangente e não sistemático, de acordo com suas próprias necessidades e interesses, é no processo de educação escolar que se dá a apropriação de conhecimentos, aliada à questão da intencionalidade social (Moura et al., 2010, p. 89).
\end{abstract}

Ao agir intencionalmente, desenvolvendo ações que visam ao favorecimento da aprendizagem de seus estudantes, o professor objetiva, em sua atividade, o motivo que o impulsiona (Rigon; Asbahr; Moretti, 2010). Tal intencionalidade deve ir ao encontro do objetivo social da escola: proporcionar ao aluno a apropriação dos conhecimentos teóricos. Rubtsov (1996) explica que o conhecimento teórico caracteriza-se, entre outras coisas, por ser uma forma universal ou uma entidade representada em pensamento e por determinar a ligação de uma relação geral do objeto com as suas manifestações concretas, isto é, o elo entre o geral e o particular.

Segundo Rosa et al. 2010, o tipo de pensamento que a organização do ensino permite ao estudante desenvolver é um dos fatores reveladores de como o conhecimento é apropriado dentro do ambiente escolar. Ao se apropriar do conhecimento teórico, o sujeito passa a ter condição de atribuir novos significados para o mundo e de ampliar e modificar as suas maneiras de interagir com a realidade que o cerca, o que "[...] permite a ele transformar a forma e o conteúdo do seu pensamento" (Rosa et al., 2010, p. 67).

Pautando-se nos pressupostos da Teoria da Atividade de Leontiev (1983; 1988) e considerando a necessidade do professor de promover o desenvolvimento dos seus estudantes no sentido da formação do pensamento teórico, a partir de sua atividade principal - o ensino -, Moura (1996; 2010) propõe a Atividade Orientadora de Ensino, a qual pode ser

Educação \& Realidade, Porto Alegre, v. 39, n. 4, p. 1003-1025, out./dez. 2014.1005 Disponível em: <http://www.ufrgs.br/edu_realidade> 
considerada como base teórico-metodológica para a organização do professor. É base teórica, sobretudo, por apresentar subsídios na Teoria da Atividade, isto é, por pensar a organização do ensino enquanto atividade; e base metodológica ao se constituir como um instrumento lógico-histórico para a organização dos conhecimentos a serem ensinados e aprendidos.

Esclarecemos que, em geral, o termo atividade é usado em um sentido amplo, sendo associado a um movimento ou à ação. No entanto, a partir da perspectiva teórica aqui adotada, empregamos esse termo tendo por base a Teoria da Atividade.

\begin{abstract}
Não chamamos todos os processos de atividade. Por esse termo designamos apenas aqueles processos que, realizando as relações do homem com o mundo, satisfazem uma necessidade especial correspondente a ele. [...] Por atividade, designamos os processos psicologicamente caracterizados por aquilo a que o processo, como um todo, se dirige (seu objeto), coincidindo sempre com o objeto que estimula o sujeito a executar esta atividade, isto é, o motivo (Leontiev, 1988, p. 68).
\end{abstract}

As diversas atividades humanas diferem-se entre si pelos seus motivos, ou seja, pela objetivação material das necessidades que a elas deram origem. Dessa maneira, um sujeito encontra-se em atividade quando o objeto de sua ação coincide com o motivo desta.

Moura (2011) explica que a constituição da atividade, que não é sinônimo de ação, dá-se na articulação entre motivos, ações e modos de ação que visam à satisfação de determinada necessidade. Para realizá-la, é preciso do motivo mobilizador do sujeito, ou de sujeitos, que atua em um grupo particular com necessidades comuns a todos, característica que pode ser percebida, por exemplo, em grupos de docentes. Assim, uma ação só se constitui como uma atividade quando cria no sujeito a necessidade de realizá-la e o motivo de tal realização coincide com o objeto.

A relação estabelecida entre a Atividade Orientadora de Ensino e o conceito de atividade, advindo de Leontiev, $(1983$; 1988) está centrada na natureza da atividade humana como fonte geral do desenvolvimento do psiquismo. Nessa relação, está a tríade defendida pela Teoria Histórico-Cultural, “[...] na qual temos um sujeito histórico (aluno), um objeto social (determinado conhecimento/conceito/conteúdo) e uma mediação cultural - o professor, seus saberes, produção cultural, a organização do ensino" (Araújo, 2003, p. 28).

Moura et al. (2010) esclarecem, ainda, que a Atividade Orientadora de Ensino mantém a estrutura de atividade que é proposta pela Teoria de Leontiev, pois tem uma necessidade (a apropriação da cultura); um motivo eficaz (a apropriação do conhecimento historicamente acumulado); objetivos (ensinar e aprender); e ações (que considerem as condições objetivas da escola). 
A partir disso podemos dizer que a busca pela organização do ensino, recorrendo à articulação entre a teoria e a prática visando à aprendizagem do aluno, constitui a atividade do professor, e que esta, por sua vez, promove a atividade do estudante ao criar nele um motivo especial para a sua atividade: estudar e aprender teoricamente. Neste movimento, o planejamento, o desenvolvimento e a avaliação constituem a intencionalidade do professor.

Como encaminhamento metodológico para o ensino de matemática, a Atividade Orientadora de Ensino compõe-se a partir de uma situação desencadeadora de aprendizagem, cujo objetivo principal está voltado à necessidade de apropriação do conhecimento por parte do estudante, de modo que suas ações sejam realizadas em busca da solução de um problema que o mobilize para a atividade de aprendizagem (Moura et al., 2010). Tal situação pode ser materializada por meio de diferentes recursos, dentre os quais se encontram os jogos, as situações emergentes do cotidiano e a história virtual.

A situação desencadeadora de aprendizagem, organizada a partir dos princípios aqui estabelecidos, deve levar o estudante à mesma necessidade que levou a humanidade ao conhecimento, à semelhança do que pode ter acontecido em certo momento histórico. Nessa organização do ensino, o elemento inicial é a síntese histórica do conceito, que possibilita ao professor ter uma visão dinâmica do movimento de sua construção, compreendendo também a contribuição das relações sociais para a criação e a solução de problemas. Ou seja, para que o professor possa elaborar o problema desencadeador da Atividade Orientadora de Ensino, é necessário que ele compreenda a essência do conceito a ser trabalhado.

Para Moura et al., a essência, isto é, a gênese do conceito, deve ser o que constitui a situação desencadeadora de aprendizagem, que está relacionado ao modo "[...] como foram aparecendo os problemas e as necessidades humanas em determinada atividade e como os homens foram elaborando as soluções ou sínteses no seu movimento lógico-histórico" (Moura et al., 2010, p. 103-104).

Os conhecimentos humanos, dentre eles o matemático, são constituídos a partir das relações sociais, culturais e históricas. Consideramos, portanto, que a matemática constitui-se como um conhecimento organizado ao longo do desenvolvimento da humanidade e que serve como um instrumento para satisfazer as necessidades instrumentais e integrativas da humanidade. Moura (2007) exemplifica afirmando que o homem, ao tomar o cajado como extensão do seu corpo, ao recolher a água em uma casca de fruta ou ao procurar uma gruta para se proteger das intempéries, dá os primeiros passos rumo a uma matemática que viria a construir-se como um instrumento lógico e simbólico para que se pudesse viver mais confortavelmente, devido ao aprimoramento das ferramentas.

Educação \& Realidade, Porto Alegre, v. 39, n. 4, p. 1003-1025, out./dez. 2014.1007 Disponível em: <http://www.ufrgs.br/edu_realidade> 
O Movimento de Formação Docente no Ensino de Geometria nos Anos Iniciais

Para Lanner de Moura, os conhecimentos matemáticos, incluindo os mais complexos, compõem a atividade humana e encontram-se no nosso cotidiano “[...] quer na estruturação do espaço que habitamos e nas máquinas que manipulamos, quer nas relações sociais, políticas e econômicas que estabelecemos para a vida conjunta e para a produção" (Moura, 2007, p. 67).

A matemática, como produto das necessidades humanas, insere-se no conjunto dos elementos culturais a serem socializados, de modo a permitir a integração entre os sujeitos e possibilitar-lhes que se desenvolvam plenamente como indivíduos, a fim de se tornarem capacitados para contribuir no desenvolvimento do coletivo.

O conteúdo matemático é constituído de signos articulados por regras que, operadas de forma lógica, produzem um resultado que tem um suporte na realidade objetiva. Isto é, ao serem aplicados na solução de problemas concretos, os conceitos deverão permitir uma intervenção objetiva na realidade. Com isto queremos dizer que os conhecimentos que vingam são aqueles que têm uma prova concreta quando testados na solução de problemas objetivos (Moura, 2007, p. 48-49).

Nessa mesma perspectiva, para Lima e Moisés (2002), a matemática é entendida como uma linguagem criada pelo homem para estudar os movimentos quantitativos e as formas do universo. Para a variação quantitativa e seus movimentos, a matemática desenvolveu uma linguagem numérica e algébrica; já para as formas do universo, uma linguagem geométrica.

A partir do que foi explicitado, entendemos que o conhecimento geométrico amplia-se na medida em que tomamos por fundamento os pressupostos da Teoria Histórico-Cultural, que compreende a construção de qualquer conhecimento matemático pelo movimento humano de satisfação de suas necessidades. Além disso, a partir dessa abordagem, no ensino de matemática, consideramos que é função do professor organizar ações que permitam ao aluno se apropriar da organização lógico-histórica dos conhecimentos.

\section{O Movimento de Organização do Ensino}

Para as discussões propostas neste artigo, voltadas à formação de professores que ensinam matemática nos anos iniciais, tendo-se em vista o desafio de ensinar Geometria, pautamo-nos em uma das ações desenvolvidas no projeto Clube de Matemática que, como já especificado, faz parte de um projeto mais amplo.

O Clube de Matemática é por nós compreendido como um espaço tanto de pesquisa quanto de ensino e aprendizagem, que envolve professores dos anos iniciais do Ensino Fundamental de quatro escolas da rede pública Estadual da cidade de Santa Maria (Rio Grande do

1008 Educação \& Realidade, Porto Alegre, v. 39, n. 4, p. 1003-1025, out./dez. 2014. Disponível em: <http://www.ufrgs.br/edu_realidade> 
Sul); estudantes dos cursos de licenciatura em Pedagogia, Matemática e Educação Especial; estudantes de pós-graduação em Educação e Educação Matemática; e a professora pesquisadora coordenadora do Clube. Cabe destacar que esse ambiente foi idealizado a partir da experiência realizada na Faculdade de Educação da Universidade de São Paulo, e que também é desenvolvida no Instituto de Matemática e Estatística da Universidade Federal de Goiás. Embora com especificidades que os distinguem entre si, os três clubes partem dos mesmos princípios teóricos e, especificamente quanto à sua organização, pautam-se na Atividade Orientadora de Ensino.

A dinâmica que adotamos no Clube de Matemática de nossa instituição centra-se em três elementos: encontros para planejamento e organização das ações; desenvolvimento das ações nas escolas em que atuam as professoras envolvidas, com a participação dos alunos de graduação e pós-graduação; e avaliação das ações. Entendemos que esses três elementos materializam a intencionalidade do professor que, a partir da sua atividade de ensino, visa a atingir uma realidade diferente da material imediata, de modo que ela torna-se impactante na realidade psicológica do sujeito que aprende. Nesse contexto, a partir da demanda das professoras, o desafio proposto foi o de organizar uma atividade de ensino $^{3}$ relacionada à Geometria e seguisse os princípios da Atividade Orientadora de Ensino. Optamos por desenvolver esta atividade tendo como base uma situação desencadeadora de aprendizagem a ser apresentada aos alunos do segundo e do terceiro ano do Ensino Fundamental, por meio de uma história virtual, que foi denominada Chapeuzinho Lilás.

Uma história virtual constitui-se de situações problema colocadas por personagens de histórias infantis, de lendas, ou da própria história da matemática como desencadeadoras do pensamento da criança, de maneira a envolvê-la na construção da solução do problema, que faz parte do contexto da história, suscitando nela uma necessidade real, mesmo sendo uma situação imaginária. A história é denominada virtual por não estar diretamente relacionada à realidade, embora ela represente uma situação problema real vivenciada pela humanidade.

$\mathrm{O}$ intuito era de que os alunos se apropriassem de conceitos iniciais de Geometria no movimento de constituição das formas geométricas a partir da relação entre o espaço e o plano.

Acompanhamos o processo de planejamento e desenvolvimento da atividade citada e, para a sua análise, optamos por fazer uso de duas sessões reflexivas ${ }^{4}$. Ibiapina (2008) propõe as sessões reflexivas para a pesquisa qualitativa a partir das ideias de Alexander Luria, que defende um método de pesquisa no qual o pesquisador centra sua análise em longas conversas ocorridas em pequenos grupos, a fim de permitir trocas de opiniões sobre determinado problema, o que ultrapassa a simples observação.

Educação \& Realidade, Porto Alegre, v. 39, n. 4, p. 1003-1025, out./dez. 2014.1009 Disponível em: <http://www.ufrgs.br/edu_realidade> 
O Movimento de Formação Docente no Ensino de Geometria nos Anos Iniciais

Todos os momentos aqui descritos foram registrados em vídeo e, posteriormente, transcritos. Além disso, embora as gravações envolvessem professores e futuros professores, nosso olhar direcionou-se às quatro docentes dos anos iniciais, participantes do grupo, uma vez que nosso interesse, nesse momento, volta-se ao processo de formação de professores em atuação.

Para melhor conhecermos nossos sujeitos, solicitamos que elaborassem, individualmente, um memorial escrito ${ }^{5}$.

Apresentamos, a seguir, as referidas professoras a partir de alguns destaques relacionados à matemática e seu ensino e, posteriormente, discorremos sobre o planejamento, o desenvolvimento e a avaliação da atividade Chapeuzinho Lilás, e o que esses momentos revelaram-nos.

\section{As Professoras e sua Prática Docente}

Por meio dos memoriais elaborado pelas professoras Carol, Gisela, Naná e Susi ${ }^{6}$, tivemos a oportunidade de conhecê-las um pouco melhor. A professora Carol tem 46 anos e trabalha há 28 nesta profissão. Ela destaca que as suas lembranças enquanto aluna de matemática nos anos iniciais desapareceram de sua memória. Para ela, isso talvez tenha acontecido por sempre tentar evitá-las, uma vez que não eram agradáveis.

Ao ingressar no Ensino Médio, ela optou pelo curso de Magistério, que a habilitou para a docência nos anos iniciais. Lembra que ficou muito feliz ao tomar conhecimento de que, nessa modalidade de estudo, aprenderia sobre a Didática da Matemática e não sobre a temida matemática aprendida no Ensino Médio.

A Didática da Matemática eu gostava, porque via um sentido para aquele estudo, diferente do Ensino Fundamental que eu não via onde aplicar aquelas fórmulas e cálculos todos (Carol-ME).

Em sua prática docente, Carol levou para a sala de aula, como referência para o ensino da matemática, aquilo que aprendeu em sua formação no curso de Magistério. A professora afirma que a sua experiência anterior com a matemática a fez optar por ensinar sempre da maneira mais prática possível. Quanto a isso ela relata que,

Ao seguir essas orientações (do curso de Magistério), eu buscava também o bom senso, já que cada realidade da turma exige uma forma diferente de trabalho. Reconheço que minha forma de trabalhar a matemática baseava-se no instinto, em experiências vivenciadas e nos livros didáticos (Carol-ME).

No decorrer de sua carreira, concluiu o curso de História, com habilitação em licenciatura. Entretanto, optou por permanecer atuando como docente nos anos iniciais.

A professora Gisela é a mais nova do grupo, tem 31 anos e atua como docente há dez. Ela iniciou seu memorial relatando uma experiên-

1010 Educação \& Realidade, Porto Alegre, v. 39, n. 4, p. 1003-1025, out./dez. 2014 Disponível em: <http://www.ufrgs.br/edu_realidade> 
cia que teve no segundo ano do Ensino Fundamental, que poderia ser um marco negativo em sua relação com a matemática: sua professora solicitou que respondesse uma questão em voz alta, cuja solução ela não sabia. Entretanto, isso fez com que Gisela se dedicasse cada vez mais a aprender matemática, tornando-se, com o decorrer dos anos, uma ótima aluna na disciplina.

Fez o curso de Magistério (nível médio), no qual sentiu falta de aprender mais matemática, uma vez que gostava muito da disciplina. Em sua carreira, continuou demonstrando interesse por essa área do conhecimento e, por isso, sempre buscou fazer com que seus alunos também gostassem, optando, sempre que possível, por levar para sua sala de aula jogos e desafios relacionados à disciplina.

No entanto, a docente admite que, muitas vezes, suas aulas recaem no método tradicional e mecânico por exigência dos pais, que cobram um caderno repleto de exercícios e cálculos.

Muitos pais não entendem a importância dos jogos para o desenvolvimento do aprendizado dessas crianças, acham que é uma perda de tempo. Eu também gostaria muito de usar o laboratório de informática, pois existem muitos jogos de matemática disponíveis e as crianças iriam gostar muito, mas a maioria dos computadores estão estragados, mas busco tornar o conteúdo considerado chato um pouco mais divertido (Gisela -ME).

A predileção de Gisela por essa disciplina evidenciou-se também na escolha do curso superior de que atualmente é aluna, Licenciatura em Matemática.

A professora Naná, que tem 49 anos e trabalha na docência há 31, destaca a participação da família como importante elemento no seu processo de escolarização e aprendizagem da matemática. Lembra-se de que seu pai a auxiliava nos deveres de casa e destaca que ele sempre a surpreendia na resolução dos exercícios. Naná recorda-se de um dia em que precisava resolver expressões numéricas, as quais não entendia, e achou que esse conteúdo, que tinha muitos números e operações, seria difícil para o pai, que conhecia apenas os cálculos cotidianos. Contudo, ele conseguiu auxiliá-la.

O fato de o pai ter pouca escolarização e somente conhecimentos práticos, mas saber realizar cálculos matemáticos, parece ter sido marcante a ponto de influir na sua prática docente, como pode ser observado na afirmação a seguir:

Nas minhas turmas, sempre me preocupei em desenvolver os conteúdos matemáticos de forma prática, respeitando o aluno e a realidade na qual ele está inserido (Naná-ME).

No Ensino Médio, no curso de Magistério, ela considerou que a disciplina de Didática da Matemática foi essencial para sua formação, pois foi devido a essa disciplina que entendeu os conteúdos dos anos

Educação \& Realidade, Porto Alegre, v. 39, n. 4, p. 1003-1025, out./dez. 2014.1011 Disponível em: <http://www.ufrgs.br/edu_realidade> 
iniciais. Naná cursou Ciências Físicas e Biológicas, mas optou por lecionar nos anos iniciais, e, por isso, também cursou Pedagogia.

Para a professora Susi, a matemática que conheceu nos anos iniciais de sua escolarização distanciou-se muito daquela ensinada nos anos finais, fazendo com que o interesse e o gosto pela disciplina não fizessem mais parte de sua vivência como aluna. Ela tem 45 anos e há 21 trabalha no Magistério.

Susi lembra-se da confecção de muitos materiais manipuláveis para o ensino de matemática, durante o curso médio de Magistério, principalmente materiais de contagem. No entanto, esses materiais nunca foram utilizados em suas práticas docentes, pois, ao terminar as aulas de Didática da Matemática, esses recursos perdiam o sentido para ela. A professora relata que nem mesmo no estágio do curso foi solicitado a ela que esses materiais fossem usados.

Porém, no curso de Pedagogia, ela descobriu uma nova matemática.

A professora de matemática do curso me fez descobrir coisas inéditas, que fazia e não sabia o porquê, me ensinou algumas operações que eu não havia aprendido no Ensino Fundamental e também me ensinou algumas coisas que eu precisava ensinar aos alunos e eu não sabia (Susi-ME).

Especificamente em relação à prática docente, chamou-nos a atenção o fato de que as quatro professoras expressaram seu receio em não sair da forma tradicional de ensinar matemática. No mesmo sentido, revelaram sua ansiedade pela busca por propiciar, em suas aulas, momentos com jogos e materiais concretos $^{7}$, como podemos notar no relato de Susi.

Eu sempre me preocupei em utilizar materiais concretos, ensinar com jogos, mas eu não me preocupava em me aprofundar no conceito matemático. Eu achava que no momento em que eles jogavam, eles aprendiam a operação, os números, para mim já era satisfatório (Susi-ME).

A professora complementa explicando que o jogo sempre foi inserido em suas aulas para contemplar a necessidade de desenvolver $o$ aspecto lúdico da matemática, para fixação de conteúdos (Susi - ME). A professora Carol também enfatiza o jogo como forma de introduzir o lúdico em sala de aula.

Para não ficar tão tradicional, trabalhar só com escrever no caderno, só fazer folhinha, tu procuras um jogo para tirar daquele clima tão tradicional (Carol-ME).

Tais afirmações das professoras reiteram as anteriores relativas à importância de buscar, em suas aulas, maneiras diferenciadas de ensinar. Além disso, de modo geral, destacamos que os memoriais evidenciam episódios marcantes da experiência de vida das professoras: um fato decepcionante na escola de Educação Básica; uma nova visão

1012 Educação \& Realidade, Porto Alegre, v. 39, n. 4, p. 1003-1025, out./dez. 2014. Disponível em: <http://www.ufrgs.br/edu_realidade> 
sobre a matemática por meio da Didática da Matemática; a matemática prática do pai que tinha pouca escolarização; a exigência dos pais por um caderno com exercícios e cálculos; a possibilidade do uso de jogos e atividades práticas ou lúdicas em sala de aula. Seus relatos trazem, ainda, fortes indícios de que esses fatos podem influenciar e direcionar a organização do ensino e a prática docente. Assim, a possibilidade de compreender a matemática a partir de uma nova perspectiva pode mobilizar o professor na busca por modos de ensinar diferenciados; as dificuldades encontradas ao se deparar com uma matemática abstrata e distante da própria realidade podem levar à busca por uma matemática considerada prática e lúdica; ou, ainda, a cobrança da sociedade (pais, dirigentes escolares etc.) pode conduzir a um ensino tradicional centrado em cálculos e operações.

Discutiremos, a seguir, a organização do ensino das professoras, quando inseridas em um movimento que exige o planejamento, o desenvolvimento e a avaliação de uma atividade de ensino de Geometria, partindo dos princípios teórico-metodológicos da Atividade Orientadora de Ensino.

\section{O Planejamento, o Desenvolvimento, a Primeira Avaliação: a decepção}

A organização da atividade de ensino sobre Geometria, o grupo do Clube de Matemática, do qual participavam quatro professoras, seis graduandos, duas pós-graduandas e a professora pesquisadora, foi iniciada com um momento de estudo e efetivou-se a partir da discussão sobre os principais conteúdos da Geometria Espacial e Plana que, tradicionalmente, fazem parte da matriz curricular dos anos iniciais do Ensino Fundamental. Além disso, houve uma discussão sobre a constituição da linguagem geométrica como um movimento do espaço ao plano, pautada em Lima e Moisés (1998). A intenção era de que esse momento de discussões e estudo promovesse reflexões sobre os aspectos históricos e matemáticos do conteúdo a ser ensinado, de modo que se chegasse à síntese histórica do conhecimento geométrico. Contudo, isso durou muito pouco tempo e não despertou grande interesse por parte grupo. Esse fato trouxe fortes indícios de que as professoras, nesse momento, estavam muito mais interessadas nos encaminhamentos metodológicos do que nos estudos teóricos.

Assim, contemplando os princípios da Atividade Orientadora de Ensino, seguiu-se à tarefa de elaboração de uma situação desencadeadora de aprendizagem que tinha por objetivo iniciar os estudos sobre Geometria com os estudantes que participavam do Clube de Matemática. A princípio o grupo encontrou muitas dificuldades, principalmente em relação à organização do problema desencadeador de aprendizagem. Após dois encontros foi concluído o planejamento e ficou decidido que a situação desencadeadora seria apresentada através de uma história

Educação \& Realidade, Porto Alegre, v. 39, n. 4, p. 1003-1025, out./dez. 2014.1013 Disponível em: <http://www.ufrgs.br/edu_realidade> 
O Movimento de Formação Docente no Ensino de Geometria nos Anos Iniciais

virtual, denominada Chapeuzinho Lilás, em forma de teatro. O enredo da história encontra-se a seguir.

\section{Chapeuzinho Lilás}

Chapeuzinho Lilás adorava estudar e tinha uma grande admiração pela matemática.

No caminho entre a casa e a escola sempre ficava encantada com todas as formas que encontrava ao seu redor, pois gostava de observar as formas geométricas.

Certo dia recebeu uma tarefa de sua professora, que era procurar de que maneira a matemática estava presente em seu cotidiano.

Chapeuzinho Lilás, a partir de suas observações, teve a brilhante ideia de representar as formas que enxergava todos os dias. Algumas delas eram parecidas com as que a professora chamava de sólidos geométricos.

Depois de prontos, colocou-os dentro de sua bolsa e foi a caminho da escola. Admirada com as flores encontradas no caminho, resolveu sentar embaixo de uma árvore para apreciá-las, mas acabou cochilando.

O lobo, muito esperto, aproveitou a oportunidade para espiar o trabalho da Chapeuzinho Lilás e percebeu que o que ela havia feito era muito melhor que o trabalho dele. Resolveu, então, trocar a sua bolsa com a dela, pois o trabalho dele tinha somente figuras planas.

Minutos depois Chapeuzinho Lilás, ao abrir a bolsa, teve uma surpresa: seu trabalho estava todo desmontado e ela só tinha agora diversas peças de figuras planas de diferentes formas e tamanhos. Ela ficou apavorada! Não sabia por onde começar a reorganizar seu material. O que teria acontecido?

Seus sólidos estavam tão bonitos quando ela sentou no parque. Mas não tinha tempo para se preocupar com isso, pois estava com pressa para chegar à escola.

Como Chapeuzinho Lilás precisava apresentar seu trabalho para a professora ainda naquele dia, resolveu montar pelo menos uma das peças que representava uma caixa com todas as faces iguais, como a caixa d'água da escola que está no pátio e que a professora chama de cubo, e, assim, mostrar um exemplo de como fez seu trabalho original!

Finalizando a encenação, Chapeuzinho Lilás propõe para os alunos o problema desencadeador de aprendizagem: Agora vocês podem me ajudar a montar o meu trabalho para mostrar para a professora? Como eu posso fazer?

1014 Educação \& Realidade, Porto Alegre, v. 39, n. 4, p. 1003-1025, out./dez. 2014. Disponível em: <http://www.ufrgs.br/edu_realidade> 
Após a encenação, os alunos dos anos iniciais eram convidados a resolver o problema da Chapeuzinho Lilás com o auxílio de material manipulável. Posteriormente, eram realizados alguns outros encaminhamentos: planificação de figuras geométricas, identificação de formas geométricas em desenhos, composição de imagens com figuras geométricas.

Na primeira sessão reflexiva, realizada alguns dias após o desenvolvimento do trabalho nas quatro escolas, as professoras destacaram novamente as dificuldades encontradas para organizar a situação desencadeadora de aprendizagem. Também enfatizaram suas dúvidas quanto a terem ou não atingido o objetivo proposto. Essa preocupação mostrou-se presente, mais especificamente, no relato de Carol, que não estava segura se a condução do que tinha sido planejado seria suficiente para contemplar o que entendia ser importante para os alunos. Carol já havia introduzido o conteúdo a ser trabalhado, antes da encenação da Chapeuzinho Lilás.

A construção histórica foi muito bem fundamentada, mas a minha turma... Eu não sei, acho que faltou algo no problema desencadeador, como eu já tinha trabalhado um pouco eu acho que é aquilo que eu te digo: quebrou a sequência e já não tinham tanta curiosidade sobre aquilo ali [...] da próxima vez eu vou trabalhar uma Atividade Orientadora de Ensino diferente, bem como ela deve ser trabalhada, aí eu acho que talvez o problema desencadeador seja mais instigante para eles (Carol-SR1).

Ao fazer menção a trabalhar uma Atividade Orientadora de Ensino diferente, bem como ela deve ser trabalhada, a professora refere-se ao fato de que não haveria necessidade de ela ter iniciado o conteúdo apresentando as figuras geométricas da forma como fazia habitualmente, pois a aprendizagem que ela esperava que os alunos tivessem poderia ser decorrente da síntese coletiva ${ }^{8}$ do problema desencadeador. Essa afirmação indicia sua compreensão de que o objetivo do problema desencadeador de uma atividade de ensino está em criar a necessidade no aluno e no fato de que esta, ao se materializar em motivos eficazes, constitui uma atividade de aprendizagem que promove o seu desenvolvimento.

Para Leontiev (1983), o motivo não só tem em si o aspecto do objetivo que interessa ao sujeito e suas propriedades estimuladoras, como também comporta os aspectos dinâmicos que o movem em direção à ação para atingir seus objetivos. Quando os motivos conferem ao sujeito um sentido pessoal são denominados motivos eficazes, e, quando apresentam somente fatores impulsores, podendo ser positivos ou negativos, são chamados de motivos apenas compreensíveis.

Carol ainda ressaltou que entendia que o problema desencadeador de uma atividade de ensino é que direciona a atividade da criança, mas que não lhe pareceu que isto tinha acontecido. Concluiu, afirmando: preciso me aprofundar mais nesse problema desencadeador aí (Carol

Educação \& Realidade, Porto Alegre, v. 39, n. 4, p. 1003-1025, out./dez. 2014.1015 Disponível em: <http://www.ufrgs.br/edu_realidade> 
- SR1). Esse foi um primeiro indício da compreensão de que a possível falha da organização inicial poderia estar na falta de conhecimentos necessários para a sua organização.

Além disso, todas as professoras comentaram que os alunos gostaram muito do teatro e da história e que, de maneira mais ou menos lenta, todos tinham conseguido montar o cubo, atendendo ao apelo da Chapeuzinho Lilás, como podemos observar na fala de duas das professoras.

Lá na escola, os alunos se envolveram muito e minha turma é uma turma agitada, é difícil fazê-los pararem quietos. Eu achei muito interessante a encenação da história, todo o encaminhamento, os alunos gostaram tanto, eles se envolveram na atividade (Gisela -SR1).

Quando os acadêmicos apareceram caracterizados lá na escola, foi novidade, porque lá nunca teve uma apresentação de teatro, alguém que se apresentasse, pessoas diferentes. Então para as crianças foi muito bom. E outra coisa, eles aprenderam a manusear, entendeu, eles tinham uma curiosidade em fazer, tanto que eles logo conseguiram montar o cubo (Naná-SR1).

A partir do que foi apresentado até aqui, podemos destacar a importância que as docentes atribuíram ao aspecto lúdico que envolveu todo o planejamento e o desenvolvimento inicial, afinal, a história virtual centrava-se na versão de uma história conhecida pelas crianças, com personagens interessantes, atores bem caracterizados, ótima encenação e participação dos alunos. Desse modo, a proposta contemplou a expectativa inicial das professoras.

Cabe, ainda, destacar outro ponto que diz respeito ao conhecimento proporcionado aos alunos, pois, ao conversarem sobre a proposta, as professoras chegaram à conclusão de que o problema apresentado para os estudantes restringiu-se a solicitar a ação de montar o cubo. Embora entendendo que este conhecimento era importante, elas passaram a ter dúvidas sobre a relevância desse encaminhamento para a aprendizagem inicial do movimento de construção da Geometria.

Não obstante, ainda não tivessem claro o que teria que ser mudado nem exatamente o porquê de não estarem mais satisfeitas, a constatação das dificuldades na elaboração do problema desencadeador e a não eficácia deste nortearam o desenvolvimento da segunda sessão reflexiva, realizada em outro dia.

\section{A Segunda Avaliação: possibilidades de discutir sobre as ações desenvolvidas}

A segunda sessão reflexiva foi desenvolvida a partir de dois momentos: a discussão de um texto ${ }^{9}$ previamente lido e a realização de um experimento formativo ${ }^{10}$.

A discussão do texto tinha o intuito de levar as professoras a refletir, novamente, sobre a construção do conhecimento geométrico no

1016 Educação \& Realidade, Porto Alegre, v. 39, n. 4, p. 1003-1025, out./dez. 2014. Disponível em: <http://www.ufrgs.br/edu_realidade> 
decorrer da história da humanidade. A pretensão era enfatizar a ideia de que a geometria constituiu-se como uma necessidade humana para a representação das formas e de que seu processo de organização deu-se em um movimento do espaço ao plano e do plano ao espaço.

Embora já tivéssemos discutido sobre o conhecimento geométrico no início do trabalho, a conclusão que chegamos à primeira sessão reflexiva, de que o objetivo da encenação da história da Chapeuzinho Lilás não havia sido atingido, trouxe fortes indícios de que as professoras não tinham se apropriado do conhecimento desejado ou, na perspectiva de Leontiev (1988), de que a ação de estudar Geometria não tinha se tornado uma atividade de aprendizagem para elas, uma vez que o objeto da atividade de estudo é o conhecimento teórico, no caso, de Geometria. A discussão que buscávamos dirigia-se à compreensão de que a Geometria é a matematização do espaço em todas as suas dimensões, constituindo-se como uma linguagem criada para a apreensão humana dos movimentos das formas, de suas variações e transformações, a partir de um processo de representação dessas formas através de desenhos, da recriação do espaço na folha de papel para, então, captar os seus movimentos quantitativos através da linguagem numérica. Nesse sentido, compactuamos com Lima e Moisés, para os quais “[...] a Geometria é a matematização do espaço para a numeralização dos movimentos das formas" (Lima; Moisés, 1998, p. 2).

Desse modo, para o experimento formativo, inicialmente assistimos juntamente com as professoras, a um vídeo ${ }^{11}$, o qual apresentava imagens da natureza, para que pudéssemos observa-las. Com isso, pretendíamos buscar formas da natureza que pudessem ser comparadas às formas matemáticas.

Posteriormente, desenvolvemos quatro ações que tinham o intuito de representar o movimento humano de apreensão e reprodução de formas naturais, do espaço para o papel. Para isso, cada componente do grupo escolheu uma forma natural e reproduziu-a com o auxílio de massa de modelar, representando o que poderia ter sido, historicamente, a manipulação artesanal através da argila. Na ação seguinte, deveria representar artisticamente essas formas, na medida em que nossas habilidades permitiram. Buscávamos, assim, subsídios para discutir sobre como o desenho também pode ser uma maneira de apreender a forma do objeto, um modo de segurá-la para si.

Passamos, então, para a terceira ação, que se constituiu na elaboração de um desenho não detalhado, numa representação das formas em configurações básicas. Ao fazer somente a reprodução do contorno do que foi observado, foi possível perceber que estes se repetem e que alguns são mais constantes. Esta capacidade de reproduzir e reelaborar as formas permitiu ao homem apreender melhor aquilo que conseguia ver e vivenciar no seu contato com a natureza. Além disso, ao reelaborar, também acabou descobrindo semelhanças e diferenças entre elas que o levaram a estabelecer critérios, propriedades e definições.

Educação \& Realidade, Porto Alegre, v. 39, n. 4, p. 1003-1025, out./dez. 2014.1017 Disponível em: <http://www.ufrgs.br/edu_realidade> 
O Movimento de Formação Docente no Ensino de Geometria nos Anos Iniciais

De acordo com Lima e Moisés (2002, p. 5), forma é a correspondência que se estabelece entre a qualidade que se quer captar e a configuração usada para representá-la. As mais comuns, recriadas pelo homem ao longo de milhares de anos, foram registradas (em papiros, papéis, etc.) e receberam nomes. Assim, na quarta ação, foi solicitada a representação da forma da natureza (escolhida inicialmente) a partir das figuras geométricas que conhecemos hoje. Esse foi o mote para discutirmos sobre as características, as nomenclaturas, as propriedades e os elementos dessas figuras, bem como sobre quais desses aspectos são relevantes para os anos iniciais do Ensino Fundamental.

As reflexões dirigiram-se, então, à possibilidade de pensar o movimento humano de apreensão das formas do espaço para o plano como norteador da organização do ensino de Geometria nos anos iniciais.

As professoras foram convidadas a repensar a atividade Chapeuzinho Lilás, sob o ponto de vista do conhecimento matemático, a partir das seguintes questões: o que elas sabiam de Geometria ao elaborar a atividade de ensino? O que de Geometria elas esperavam que os alunos aprendessem? O que consideravam, naquele instante, importante para organizar o ensino que visasse à apropriação dos conceitos iniciais de Geometria?

Uma das primeiras conclusões a que chegaram foi a de que a situação desencadeadora de aprendizagem que haviam organizado para o Clube de Matemática não contemplou o movimento histórico de construção do conceito, como podemos observar na fala de Susi:

As crianças realmente se interessaram em fazer [as ações propostas], mas não ficou claro aquela necessidade histórica, humana do conceito (Susi SR2).

Ao tomarmos por base os princípios da Atividade Orientadora de Ensino, entendemos que pensar em uma situação desencadeadora de aprendizagem implica pensar em um problema que leve o estudante à mesma necessidade que levou a humanidade ao conceito em questão. Assim,

[...] ao utilizar a situação-problema na atividade orientadora não procuramos apenas a lógica do objeto - do conteúdo - ou a do sujeito - seus interesses e dinâmica. Contemplamos os dois movimentos: o do sujeito e o do objeto. Isso não significa apenas agrupá-los como dois aspectos importantes a ser levados em conta na organização do ensino, mas considerá-los em uma unidade. Essa unidade está presente no movimento de produção conhecimento e também de sua apropriação pelos sujeitos (Moura; Sforni; Araújo, 2011, p. 41).

Embora antes do planejamento houvesse sido discutida a possibilidade de criar uma situação desencadeadora que proporcionasse a

1018 Educação \& Realidade, Porto Alegre, v. 39, n. 4, p. 1003-1025, out./dez. 2014 Disponível em: <http://www.ufrgs.br/edu_realidade> 
percepção do movimento histórico do conceito (princípio da Atividade Orientadora de Ensino), tal criação não ocorreu. A ênfase da atividade ficou somente nas formas geométricas. Isso já havia sido percebido na primeira sessão reflexiva e, nesta, foi reiterado por Gisela e Naná.

Eu acho que o conteúdo contemplado foi apenas a parte da planificação do cubo (Gisela-SR2).

Na parte que a gente fez as atividades, ficou com uma defasagem e não ficou bem claro, ficou somente a parte que era a representação do cubo (Naná -SR2).

Gisela e Naná referiram-se ao fato de que o problema desencadeador proposto por Chapeuzinho Lilás centrava-se na planificação de uma única figura geométrica espacial (o cubo), cujas seis faces eram compostas por uma única figura geométrica plana (quadrado).

O enfoque no cubo tinha sido a opção inicial aprovada por todos, pois lhes parecia o mais importante a ser ensinado. Esse fato nos leva a perceber que essa organização foi norteada pelos conhecimentos que as professoras tinham sobre Geometria e que estavam centrados nas formas geométricas básicas, como aponta a fala de Susi.

Quando se fala em Geometria, a primeira coisa que me vem à cabeça são figuras geométricas, ângulos (Susi-SR1).

Ademais, ao enfatizarem, com satisfação, que os alunos interessaram-se pela história da Chapeuzinho Lilás, como já havíamos destacado anteriormente, pudemos observar que, na organização inicial, a preocupação que ficou mais evidente foi a de uma organização que despertasse o interesse das crianças. Desse modo, percebemos que, embora o aspecto lúdico seja considerado como importante na Atividade Orientadora de Ensino, não é o principal. Assim, entendemos que as professoras foram movidas por uma necessidade, já destacada em seus memoriais, relacionada ao esforço de desenvolver um ensino de matemática que fosse agradável para os alunos.

Assim sendo, a necessidade (organizar uma atividade lúdica) não se concretizou como um motivo que coincidisse com o objeto da atividade de ensino, que é o conhecimento, no caso de Geometria, e que deve constituir-se a partir de uma necessidade para os alunos (Leontiev, 1983; 1988). Ou seja, pautados na teoria que nos fundamenta, poderíamos afirmar que as ações das professoras na organização da situação desencadeadora Chapeuzinho Lilás partiram de uma necessidade que não estava direcionada ao objeto da atividade de ensino.

A constatação de que o movimento histórico não foi contemplado aponta para a possibilidade de que a ampliação dos estudos, na segunda sessão reflexiva, e as discussões durante a realização do experimento formativo permitiram que as professoras se apropriassem de novos conhecimentos geométricos, a partir de uma perspectiva diferente da

Educação \& Realidade, Porto Alegre, v. 39, n. 4, p. 1003-1025, out./dez. 2014.1019 Disponível em: <http://www.ufrgs.br/edu_realidade> 
que normalmente se utiliza na educação escolar, que, até então, não possuíam, ou que não foi por elas vivenciado em sua escolarização.

A discussão a seguir centrou-se especificamente nos encaminhamentos dados a partir do experimento formativo. O elemento que mais se destacou nas falas das professoras foi a importância de relacionar o conhecimento geométrico com as formas conhecidas pelas crianças.

Susi destacou a maneira como realizamos o estudo teórico do conhecimento geométrico. Segundo ela, o texto utilizado foi esclarecedor:

Eu li [o texto] ontem e pensei: como é que eu não vi isso antes? Isso foi bem importante na nossa atividade [...] nós não saímos com as crianças para observar se na natureza havia algumas formas, não fizemos nada disso... (Susi-SR2).

Apesar de, no momento do planejamento inicial, as docentes terem colocado que já possuíam conhecimentos relacionados à Geometria, ao voltarem novamente sua atenção e terem a oportunidade de discutir sobre esse aspecto, perceberam que seus conhecimentos iniciais não foram suficientes para organizar uma atividade de ensino que oportunizasse a aprendizagem de seus alunos. Essa constatação, no contexto do que discutimos, aqui, até agora, permite destacar que o conhecimento matemático do professor pode ser um elemento norteador da organização do seu ensino. Assim, podemos entender que a atividade pedagógica está diretamente relacionada ao conhecimento que o professor tem do seu objeto de ensino.

Passamos, então, a discutir com as professoras a seguinte questão: o que realmente é essencial na aprendizagem da Geometria nos anos iniciais? Susi posiciona-se nessa discussão:

Agora isso para mim está claro, que [o ensino de] Geometria seria isso, observar a natureza e transportar isso, para o papel... Olhando agora parece que não tinha muito sentido o encaminhamento que foi dado no início da história, porque foi direto para o cubo e faltou mesmo essa parte da essência do conhecimento (Susi-SR2).

Esse posicionamento é reiterado pelas colegas e corrobora a visão de que tudo que constitui a Geometria é um esforço do trabalho humano de compreender e apreender o movimento figurativo da natureza. "É a partir das formas naturais, e com elas, que criamos as formas elaboradas que constituem as categorias geométricas: o cubo, o paralelepípedo, a esfera, a pirâmide, o quadrado, o triângulo [...]" (Lima e Moisés, 1998, p. 3).

As discussões levaram as professoras a concluir que não se pode considerar que a figura geométrica constitui a essência do conhecimento geométrico, mas produto em forma de síntese da formalização humana de representação do espaço. E, nessa perspectiva, o ensino de geometria para os anos iniciais não poderia ser iniciado com o enfoque único nas figuras geométricas. Essa conclusão traz indícios da atribui-

1020 Educação \& Realidade, Porto Alegre, v. 39, n. 4, p. 1003-1025, out./dez. 2014 Disponível em: <http://www.ufrgs.br/edu_realidade> 
ção, por parte das professoras, de novos sentidos ao conhecimento geométrico e à organização do ensino, e, consequentemente, mudanças qualitativas da ação docente. E foi isso que lhes permitiu discutir e avaliar as ações realizadas levando à possibilidade de entender porque não tinham oportunizado a aprendizagem esperada dos alunos. Para Moura (2000) é possível acompanhar a mudança de qualidade dos professores na medida em que eles entendem o seu processo de aprendizagem e adquirem certa autonomia para continuar a mudar.

\section{Considerações Finais}

Ao nos propormos a escrever o presente artigo, objetivamos discutir sobre a formação de professores que ensinam matemática nos anos iniciais do Ensino Fundamental, tendo em vista os desafios de organizar uma Atividade Orientadora de Ensino de Geometria.

Para isso, revelamos a organização de um grupo do qual participavam quatro professoras que planejaram, desenvolveram e avaliaram uma proposta, movidas pela intencionalidade de organizar o ensino pautado em princípios teórico-metodológicos previamente definidos.

No planejamento inicial, surgiram dúvidas e dificuldades quanto à elaboração de uma situação desencadeadora de aprendizagem que despertasse nos alunos a necessidade de desenvolvê-la de modo a contemplar o movimento humano da organização da linguagem geométrica. A organização da Atividade orientadora de ensino, denominada Chapeuzinho Lilás, aceita em um primeiro momento, posteriormente foi avaliada como não adequada para a aprendizagem desejada.

O acompanhamento do movimento dessa organização e, em especial, das duas sessões reflexivas, incitaram-nos a destacar dois pontos que consideramos relevantes em relação às discussões sobre a formação de professores que ensinam matemática nos anos iniciais do Ensino Fundamental.

O primeiro deles refere-se ao conhecimento matemático das professoras, que teve influência direta na organização do ensino, exercendo a função de elemento norteador de suas ações. Isso ficou evidente no planejamento inicial quando, apesar de terem clara a importância da elaboração de uma situação desencadeadora de aprendizagem que contemplasse o movimento histórico de sistematização da linguagem geométrica, os seus conhecimentos levaram-nas a centrarem-se apenas nas figuras geométricas.

Ainda em relação ao conhecimento matemático, cabe lembrarmos o caso da professora Gisela. Por cursar o quarto semestre de Licenciatura em Matemática, com habilitação em licenciatura, poderíamos esperar que ela se valesse de conhecimentos matemáticos adquiridos em seus estudos acadêmicos para aprimorar a sua prática pedagógica ao ensinar essa disciplina. Essa expectativa faz-se possível porque, em-

Educação \& Realidade, Porto Alegre, v. 39, n. 4, p. 1003-1025, out./dez. 2014.1021 Disponível em: <http://www.ufrgs.br/edu_realidade> 
O Movimento de Formação Docente no Ensino de Geometria nos Anos Iniciais

bora esse curso objetive a formação de professores para os anos finais e para o Ensino Médio, é pertinente supormos que a aprendizagem de conhecimentos matemáticos mais avançados exija a discussão de conhecimentos básicos. No entanto, segundo a docente, isso ainda não aconteceu, e ela sente-se até desestimulada com esse curso, porque não parte para a Educação Matemática, é mais para formar matemáticos mesmo (Gisela - SR2).

A constatação de que, no curso de Licenciatura em Matemática, não se aprende matemática para ensinar associada às críticas que são direcionadas aos professores dos anos inicias que não sabem esse conteúdo e ao que ressaltamos anteriormente, referente à influência do conhecimento na ação docente, levam-nos a refletir sobre quais conhecimentos matemáticos o professor deve ter, que lhe permitam ensinar matemática de maneira mais eficaz, fazendo com que seus alunos aprendam. Em outras palavras, formulamos a seguinte questão: o modo como os professores são ensinados lhes permite uma apropriação do conhecimento que subsidie a organização do ensino de matemática? A partir dos referenciais da Teoria Histórico-Cultural, acreditamos, assim como Moura, Sforni e Araújo (2011, p. 42) que “[...] o conhecimento produzido só se constitui efetivamente como tal quando inserido na atividade humana que lhe confere significado social e sentido pessoal". Contudo, essa compreensão dificilmente está presente nas atuais propostas de formação de professores.

O segundo ponto que gostaríamos de ressaltar - que, até então, não tínhamos nos referido especificamente, mas que os dados permitem-nos apontar - diz respeito à dimensão colaborativa do desenvolvimento das ações, tomada como uma das premissas principais da organização das nossas ações, das quais a aqui apresentada faz parte. Partimos da compreensão de que o compartilhamento, como ação básica da dimensão colaborativa, fornece condições para que todos os sujeitos envolvidos tenham a possibilidade de refletir sobre o que se pretende fazer e o que foi feito. Essa reflexão é importante na medida em que permite que as ações ultrapassem os limites individuais (Rubtsov, 1996) e que a atividade coletiva, experiência social, transforme-se em uma atividade individual, experiência do indivíduo.

No caso aqui apresentado, foi o compartilhamento das ações que propiciou condições para que as discussões e as reflexões sobre os encaminhamentos das ações conduzissem a novas aprendizagens por parte das professoras. Pontuamos que Vigotski (2000) explicita que o desenvolvimento psíquico do sujeito acontece na passagem das formas coletivas para as formas individuais, ou seja, no processo de internalização de transformação do interpsíquico para o intrapsíquico.

Pautados nisso, entendemos que as ações desenvolvidas constituíram-se como formadoras tanto do ponto de vista do conhecimento matemático quanto da docência, uma vez que, como afirma Moura (2011),

1022 Educação \& Realidade, Porto Alegre, v. 39, n. 4, p. 1003-1025, out./dez. 2014 Disponível em: <http://www.ufrgs.br/edu_realidade> 
a análise do coletivo - que tem como referência a produção teórica sobre o ensino, a aprendizagem, a experiência do grupo - conduz à reflexão, a qual leva a outro nível de compreensão da atividade pedagógica.

Finalizando, destacamos que a possibilidade de oferecer um espaço permanente de formação docente, que envolva a parceria entre escola e universidade, por meio da participação de professores e futuros professores vinculados à Escola Básica e à instituição de ensino superior, como é o caso do Clube de Matemática, tem se mostrado como promissor na perspectiva da formação de todos os envolvidos. E é essa interação, de diferentes sujeitos que ocupam diferentes espaços na educação, que mobiliza nossas ações de estudos e de pesquisas.

Recebido em 25 de março de 2014 Aprovado em 06 de junho de 2014

\section{Notas}

1 O projeto Educação Matemática nos anos iniciais do Ensino Fundamental: princípios e práticas da organização do ensino é desenvolvido em quatro núcleos: Universidade Federal de Santa Maria (UFSM), Universidade de São Paulo (USP campus de São Paulo e campus de Ribeirão Preto) e Universidade Federal de Goiás (UFG), sendo coordenado pelo professor Doutor Manoel Oriosvaldo de Moura.

2 A denominação feminina deve-se ao fato de que as quatro participantes eram mulheres.

3 Tomando por base nossos pressupostos teóricos, o termo atividade está diretamente relacionado à Teoria da Atividade. A partir deste momento, quando nos referirmos ao trabalho realizado, estaremos o tratando como uma atividade de ensino, visto que a intenção, ao organizá-lo, foi a de que se constituísse como tal.

4 As falas transcritas das sessões reflexivas são identificadas com o nome da professora e a identificação SR1 (Sessão Reflexiva 1) ou SR2 (Sessão Reflexiva 2).

5 O memorial deveria contemplar suas lembranças sobre suas trajetórias em relação ao ensino e aprendizagem da matemática. As transcrições de trechos do memorial escrito são identificadas com o nome da professora, seguidas de ME.

6 Os nomes são fictícios, escolhidos pelas professoras.

7 Ao usar os termos "materiais concretos" ou "atividades concretas", as professores referem-se ao desenvolvimento de ações com materiais manipuláveis diversos.

8 A síntese coletiva refere-se à solução da situação problema na Atividade Orientadora de Ensino deve ser realizada na coletividade, a partir de situações que exigem o compartilhamento de ações.

9 Este texto foi organizado pelas autoras desse artigo, a partir dos pressupostos teóricos e metodológicos que norteiam as ações de pesquisa e faz parte do relatório de atividades do projeto já citado, ao qual a pesquisa aqui apresentada está vinculada. O mesmo referia-se ao movimento lógico-histórico de construção do conhecimento geométrico.

Educação \& Realidade, Porto Alegre, v. 39, n. 4, p. 1003-1025, out./dez. 2014.1023

Disponível em: <http://www.ufrgs.br/edu_realidade> 
O Movimento de Formação Docente no Ensino de Geometria nos Anos Iniciais

10 A partir de Davidov (1988), entendemos experimento formativo como a possibilidade de o investigador intervir de maneira ativa nos processos psicológicos que está estudando. Este experimento constitui-se em um conjunto de ações de organização de uma proposta didática com vistas ao desenvolvimento dos indivíduos.

11 O vídeo exibido foi acessado no dia 15 de dezembro de 2012. Disponível em: <http://www.youtube.com/watch?v=aJT9F2oHrSg >.

\section{Referências}

ARAÚJO, Elaine Sampaio. Da Formação e do Formar-se: a atividade de aprendizagem docente em uma escola pública. 2003. $173 \mathrm{f}$. Tese (Doutorado em Educação) - Faculdade de Educação da Universidade de São Paulo, São Paulo, 2003.

CURI, Edda. A Matemática e os Professores dos Anos Iniciais. São Paulo: Musa Editora, 2005.

DAVIDOV, Vasili Vasilievich. La Enseñanza Escolar y el Desarrollo Psíquico: investigación psicológica teórica y experimental. Moscou: Progresso, 1988.

IBIAPINA, Ivana Maria Lopes de Melo. Pesquisa Colaborativa: investigação, formação e produção de conhecimentos. Brasília: Líber, 2008.

LANNER DE MOURA, Anna Regina. Movimento Conceptual em Sala de Aula. In: MIGUEIS, Marlene; AZEVEDO, Maria da Graça. Educação Matemática na Infância. Vila Nova de Gaia: Gailivros, 2007. P. 65-84.

LEONTIEV, Alexei Nikolaevich. Actividad, Conciencia e Personalidad. Havana: Editorial Pueblo y Educacion, 1983.

LEONTIEV, Alexei Nikolaevich. Uma Contribuição à Teoria do Desenvolvimento da Psique Infantil. In: VIGOTSKII, Lev Semenovich; LURIA, Alexander Romanovich; LEONTIEV, Alexei Nikolaevich. Linguagem, Desenvolvimento e Aprendizagem. 5. ed. São Paulo: Ed. Ícone, 1988. P. 59-83.

LIMA, Luciano Castro; MOISÉS, Roberto Perides. A Forma: movimento e número: proposta didática para a aprendizagem da linguagem geométrica. São Paulo: Programa Integrar - CUT, SP, 1998.

LIMA, Luciano Castro; MOISÉS, Roberto Perides. Uma Leitura do Mundo: forma e movimento. São Paulo: Escolas Associadas, 2002.

MOURA, Manoel Oriosvaldo de; SFORNI, Marta Sueli de Faria; ARAÚJO, Elaine Sampaio. Objetivação e Apropriação de Conhecimentos na Atividade Orientadora de Ensino. Revista Teoria e Prática da Educação, v. 14, n. 1, p. 39-50, jan./ abr. 2011. Disponível em: <www.dtp.uem.br/rtpe/volumes/v14n1/04.pdf>. Acesso em: 10 ago. 2012.

MOURA, Manoel Oriosvaldo de (Org.). Controle da Variação de Quantidade: atividades de ensino. Textos para o ensino de Ciências n. 7. Oficina Pedagógica de Matemática. São Paulo: USP, 1996.

MOURA, Manoel Oriosvaldo de. O Educador Matemático na Coletividade de Formação: uma experiência com a escola pública. 2000. 131 f. Tese (Livre-Docência em Educação) - Universidade de São Paulo, São Paulo, 2000.

MOURA, Manoel Oriosvaldo de. Matemática na Infância. In: MIGUEIS, Marlene; AZEVEDO, Maria da Graça. Educação Matemática na Infância. Vila Nova de Gaia: Gailivros, 2007. P. 39-64.

1024 Educação \& Realidade, Porto Alegre, v. 39, n. 4, p. 1003-1025, out./dez. 2014. Disponível em: <http://www.ufrgs.br/edu_realidade> 
MOURA, Manoel Oriosvaldo de et. al. A Atividade Orientadora de Ensino como Unidade entre Ensino e Aprendizagem. In: MOURA, Manoel Oriosvaldo de (Org.). A Atividade Pedagógica na Teoria Histórico-Cultural. Brasília: Líber, 2010. P. 81-110.

MOURA, Manoel Oriosvaldo de. A Aprendizagem Inicial do Professor em Atividade de Ensino. In: LOPES, Anemari Roesler Luersen Vieira; TREVISOL, Maria Teresa Ceron; PEREIRA, Patrícia Sândalo (Org.). Formação de Professores em Diferentes Espaços e Contextos. Campo Grande: Editora UFMS, 2011. P. 87-102.

NACARATO, Adair Mendes; MENGALI, Brenda Leme da Silva; PASSOS, Carmen Lucia Brancaglion. A Matemática nos Anos Iniciais do Ensino Fundamental: tecendo fios do ensinar e do aprender. Belo Horizonte: Autêntica, 2009.

RIGON, Algacir José; ASBAHR, Flavia da Silva Ferreira; MORETTI, Vanessa Dias. Sobre o Processo de humanização. In: MOURA, Manoel Oriosvaldo (Org.). A Atividade Pedagógica na Teoria Histórico-Cultural. Brasília: Líber, 2010. P. 13-44. ROSA, Josélia Euzébio et al. As Particularidades do Pensamento Empírico e do Pensamento Teórico na Organização do Ensino. In: MOURA, Manoel Oriosvaldo (Org.). A Atividade Pedagógica na Teoria Histórico-Cultural. Brasília: Líber, 2010. P. 67-80.

RUBTSOV, Vitaly. A Atividade de Aprendizagem e os Problemas Referentes à Formação do Pensamento Teórico dos Escolares. In: GARNIER, Catherine et al. (Org.). Após Vygotsky e Piaget: perspectiva social e construtivista - Escola russa e ocidental. Tradução de Eunice Gruman. Porto Alegre: Artes Médicas, 1996. P. 129-137.

VIGOTSKI, Lev Semenovich. A Construção do Pensamento e da Linguagem. Tradução de Paulo Bezerra. São Paulo: Martins fontes, 2000.

Anemari Roesler Luersen Vieira Lopes é doutora em Educação (FE-USP). Professora do Centro de Educação; do Programa de Pós-Graduação em Educação e do Programa de Pós Graduação em Educação Matemática e Ensino de Física da UFSM. Líder do Grupo de Estudos e Pesquisas em Educação Matemática (GEPEMat/UFSM) e membro do Grupo de Estudos e Pesquisa sobre a atividade Pedagógica (GEPAPe/USP).

E-mail: anemari.lopes@gmail.com

Halana Garcez Borowsky Vaz é licenciada em Pedagogia e Mestra em Educação pela Universidade Federal de Santa Maria. Doutoranda em Educação do Programa de Pós-Graduação em Educação (PPGE/UFSM). Pesquisadora no Grupo de Estudos e Pesquisas em Educação Matemática (GEPEMat/ UFSM).

E-mail: halanagarcezborowsky@yahoo.com.br 